\title{
Erratum to: Elasticity, thermal stability and bioactivity of polyhedral oligomeric silsesquioxanes reinforced chitosan-based microfibres
}

\author{
S. L. Chew $\cdot$ K. Wang $\cdot$ S. P. Chai $\cdot$ \\ K. L. Goh
}

Published online: 8 September 2013

(C) Springer Science+Business Media New York 2013

\section{Erratum to: J Mater Sci: Mater Med}

\section{(2011) 22:1365-1374 \\ DOI 10.1007/s10856-011-4318-3}

In Fig. 4 of this article, a typographical error was made in reporting the mechanical parameters. The y-axis label of Fig. 4b should be 'Stiffness, $E$ [GPa]'; the y-axis label of Fig. $4 \mathrm{~d}$ should be 'Fracture strain energy density, $u[\mathrm{MPa}]$ '. This error does not affect the caption of Fig. 4 or the conclusion of the paper. The correct graph is shown below. The authors would like to apologize for any confusion the error may have caused.

The online version of the original article can be found under doi:10.1007/s10856-011-4318-3.

\section{S. L. Chew}

School of Chemical and Biomedical Engineering, Nanyang

Technological University, Singapore 637457, Singapore

K. Wang

Department of Chemical Engineering, The Petroleum Institute,

Abu Dhabi, United Arab Emirates

S. P. Chai · K. L. Goh $(\bowtie)$

School of Engineering, Monash University Sunway Campus,

Selangor 46150, Malaysia

e-mail: goh.kheng.lim@eng.monash.edu.my 
Fig. 4 Bar charts showing a strength, $\sigma$, b stiffness, $E$, c elastic strain energy density, $u^{\prime}$, and $\mathbf{d}$ fracture strain energy density, $u$, versus POSS concentration $(\% \mathrm{w} / \mathrm{w})$. Vertical bars indicate standard error.

Results from the control group $(0 \%(\mathrm{w} / \mathrm{w}))$ are shown here for the purpose of comparison
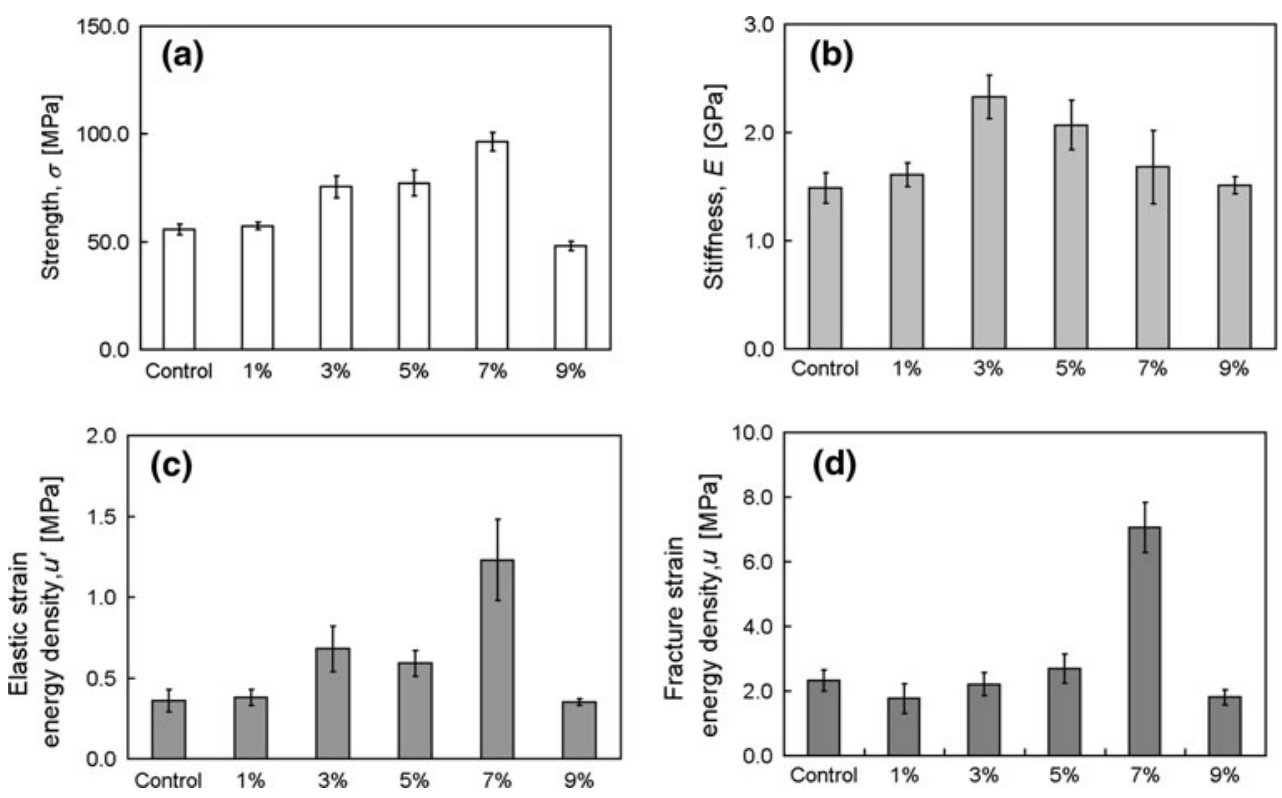